\title{
DC-OVA Vaccine
}

National Cancer Institute

\section{Source}

National Cancer Institute. DC-OVA Vaccine. NCI Thesaurus. Code C73986.

An autologous, multivalent dendritic cell vaccine targeting ovarian cancer with potential immunostimulating and antineoplastic activities. DC-OVA vaccine is produced in vitro by pulsing autologous dendritic cells with killed autologous primary ovarian tumors as a source of tumor-associated antigens (TAAs); the pulsed DCs are then matured using various cytokines. Upon administration, DC-OVA vaccine may stimulate a cytotoxic T lymphocyte $(C T L)$ response against ovarian cancer TAA-expressing ovarian cancer cells. 